\title{
DO DISCURSO DA VALORIZAÇÃO À REALIDADE DA PRECARIZAÇÃO: OS PROFISSIONAIS DA EDUCAÇÃO NO CONTEXTO DO FUNDEF E DO FUNDEB*
}

\author{
Wellington Ferreira de Jesus, \\ da Universidade Católica de Brasília (UCB).
}

\begin{abstract}
Resumo: O presente trabalho, construído como estudo exploratório a partir de uma pesquisa sobre as origens históricas e as perspectivas da política de fundos constitucionais no contex to do financiamento da educação básica no Brasil, discute a política de valorização do magistério segundo os referidos fundos constitucionais, destacadamente o Fundo de Valorização do Ensino Fundamental e de Valorização do Magistério (Fundef) e o Fundo de Desenvolvimento da Educação Básica e de Valorização dos Profissionais da Educação (Fundeb). Realizou-se um levantamento no conjunto da legislação pertinente ao financiamento da educação, em particular, da educação básica brasileira, a Constituição Federal de 1988, a LDB (Lei nº 9.394/1996), Emendas Constitucionais, resoluções e pareceres do Conselho Nacional de Educação e do Ministério da Educação (MEC) e literatura pertinente. No fim, destaca-se que é possível considerar que, historicamente, a problemática que envolve a valorização do magistério se apresenta como um dos assuntos que, como integrante das políticas educacionais e do financiamento, assume a centralidade no discurso, embora, em geral, na prática permaneça relegada a um segundo plano ou negligenciada pelo poder público.

Palavras-Chave: Financiamento da educação básica. Precarização. Valorização dos profissionais da educação. Fundef. Fundeb.
\end{abstract}

O presente trabalho, um estudo exploratório a partir de uma pesquisa sobre as origens históricas, o desenvolvimento e as perspectivas da política de fundos constitucionais no contexto do financiamento da educação básica no Brasil, discute a política de valorização do magistério segundo os

\footnotetext{
* Artigo recebido em 27/04/2012 e aprovado em 22/01/2013.
} 
referidos fundos constitucionais, destacadamente o Fundo de Valorização do Ensino Fundamental e de Valorização do Magistério (Fundef) e o Fundo de Desenvolvimento da Educação Básica e de Valorização dos Profissionais da Educação (Fundeb). Realizou-se um levantamento no conjunto da legislação pertinente ao financiamento da educação, em particular, da educação básica brasileira, a Constituição de 1988 (CF), a Lei de Diretrizes e Bases da Educação Nacional (LDB), Emendas Constitucionais (EC), resoluções e pareceres do Conselho Nacional de Educação (CNE) e do Ministério da Educação (MEC), bem como foi feito um levantamento da literatura pertinente. No fim do artigo, consideramos que, historicamente, a problemática da valorização dos profissionais da educação é uma tema que, como integrante das políticas educacionais e do financiamento, assume centralidade no discurso, embora, em geral, na prática permaneça relegada a um segundo plano ou negligenciada pelo poder público.

DAS ORIGENS DA PROPOSTA DE VALORIZAÇÃO PROFISSIONAL À PRECARIZAÇÃO NO FUNDEF

Para compreender a relevância da valorização dos profissionais da educação, no contexto do financiamento desse setor, tomou-se como referência a proposta de Anísio Teixeira, formulada na década de 1960, para a criação de um fundo de financiamento do ensino primário. Para calcular o custo padrão, Anísio partiu do salário do magistério. Conforme Amaral (2001, p. 278-279), "na definição dessa retribuição ao trabalho docente, a sua preocupação foi a de contar com profissionais 'capazes e preparados',' o que ocorreria com "um salário não inferior a 1,5 salário mínimo regional (1,5 x S.M.) - vigente à época - para uma carga de trabalho diário de 6 horas". No fim da década de 1980, a temática retoma força com o processo de redemocratização e o retorno ao Estado democrático de direito no Brasil, proposto pelo art. 206 e pelo ADCT 67 da Constituição Federal (CF) de 1988, além das emendas constitucionais (EC) que instituíram o Fundef e o Fundeb.

No fim do século $X X$, a concepção de origem do Fundef propunha "corrigir distorções históricas", inclusive no aspecto da valorização do magistério. Constituído na perspectiva de uma "política educacional focalizada", o Fundef redistribuía recursos entre estados, municípios e Distrito Federal, privilegiando o ensino fundamental. Caso os governos estaduais, municipais e distrital não conseguissem cumprir o valor mínimo anual por aluno, a União complementaria esse valor. 
Constava da Lei n 9.424/1996, a valorização do magistério. O art. $9^{\circ}$ determinava que até $1^{\circ}$ de julho de 1997 os planos de carreira e a valorização salarial deveriam ser organizados, conforme as diretrizes do Conselho Nacional de Educação (CNE) (BRASIL, 1996). Mas como o MEC não homologou o Parecer $n^{\circ}$ 02/1997, que estipulava uma remuneração média e a fixação de um piso salarial nacional, o CNE elaborou novo parecer, o de $n^{\circ}$ 03/1997, que, além de restringir-se ao ensino fundamental, fixava uma remuneração média calculada a partir da razão entre 15\% da receita líquida de impostos e a matrícula no ensino fundamental regular para uma jornada de 20 horas/ aula e 5 horas/atividade.

O art. $9^{\circ}$ da Lei $n^{\circ}$ 9.424/1996 propunha a valorização do magistério, uma das reivindicações consideradas históricas dos professores brasileiros. Semeghini (2001a, p. 14) afirmou que "uma das ideias centrais na concepção do Fundo é a de valorização do magistério". Nesse sentido, em 1998, o MEC, por meio da Fundação Instituto de Pesquisas Econômicas da Universidade de São Paulo (Fipe/USP), realizou uma pesquisa em 300 redes públicas de ensino fundamental, compreendendo a totalidade das redes estaduais e do Distrito Federal, as redes municipais pertencentes às 26 capitais e mais 273 redes de municípios, tendo por referência a questão salarial, a formação e a capacitação e carência de docentes.

Entre os resultados, destaca-se o fato de que, em 1998, aproximadamente $56 \%$ dos profissionais que atuavam no ensino fundamental não possuíam a licenciatura e, em grande parte, haviam completado apenas o ensino fundamental; eram os "professores leigos". Também constatou-se que apenas $23 \%$ das redes pesquisadas desenvolviam programas de capacitação e aperfeiçoamento dos professores sem licenciatura.

Semeghini (2001a, p. 19) também avaliou que entre 1998 e 2001 houve uma elevação salarial média para os professores, pois

os dados disponíveis confirmam a melhoria nos níveis salariais médios do professorado. Os reajustes foram maiores nas redes municipais em todas as regiões, o que é ainda mais significativo, levando-se em conta que foi nessas redes que aumentou substancialmente o número de docentes. Entretanto, mesmo as redes estaduais reajustaram seus salários em níveis superiores ao da inflação no período. Os maiores índices foram concedidos aos profissionais dos municípios e regiões mais pobres, com o que reduziu-se a distância entre seus vencimentos e a média das demais regiões. No Norte e no Nordeste, em que pese transferirem recursos aos municípios, os Estados concederam aumentos médios em suas redes bem maiores do que os estabelecidos no Sul, Sudeste e Centro-Oeste, provavelmente por causa da emulação com esses mesmos municípios. 
Costa e Duarte (2004), em um estudo sobre a valorização do magistério no estado de Minas Gerais, chamaram a atenção para o fato de que, considerados os limites e as possibilidades, o Fundef funcionou como um significativo mecanismo indutor para o magistério mineiro. Tomando como referência os dados da pesquisa da Fipe/USP, citada por Semeghini (2001a, 2001b), no que dizia respeito à valorização do magistério, Arelaro (2008, p. 13) afirmou que

na pesquisa sobre avaliação da implantação do FUNDEF, realizada em doze Estados, constatou-se que nos municípios em que os Prefeitos não pagavam sequer o salário mínimo, ou pagavam meio salário mínimo aos professores, os chamados "escravos da educação", em termos salariais, obtiveram, efetivamente, a correção dessa injustiça. Os Prefeitos passaram, a partir de 1999, a pagar o salário mínimo. Mas, para isso, não era necessário o FUNDEF, bastava o cumprimento dos dispositivos da Constituição Federal de 1988, que proíbe qualquer trabalhador de ganhar menos que um salário mínimo por jornada de trabalho. É interessante observar que isto aconteceu, somente, nos municípios pequenos, pois nos grandes municípios, e nos que já possuíam redes tradicionais de ensino, com estatutos de magistério e/ou planos de carreira em desenvolvimento, constatou-se que, depois do FUNDEF, poucos foram os ganhos salariais. O que se obteve, de maneira geral, foi o estabelecimento de gratificações anuais ao magistério - no "acerto de contas" dos $60 \%$ que deveriam ser gastos. É importante destacar que nos municípios com redes municipais, mesmo nos municípios pobres, grosso modo, já se gastavam os $60 \%$ em pagamento de pessoal. O Governo Federal também sabia disso, tanto que não foi surpresa constatar que os gastos municipais com salários, já em 2000, atingiam mais de 70\% dos recursos do FUNDEF, e $66 \%$ do total dos recursos que deveriam ser investidos no ensino fundamental, conforme dados divulgados no próprio site do MEC.

Ressaltamos que a política salarial adotada para o magistério, bem como outros setores públicos durante a gestão FHC (1995-2002), privilegiou a concessão de "gratificações" não incorporadas ao salário e, portanto, o salário base permaneceu congelado (COSTA; DUARTE, 2004; DAVIES, 2001).

Sobre a questão da valorização do magistério, Mendes (2004, p. 7) afirmou que "o aumento na remuneração dos professores, viabilizado pelo direcionamento de $60 \%$ dos recursos do Fundo para este fim, também deve ter contribuído para atrair profissionais mais qualificados para os quadros do ensino fundamental". Ainda segundo ele, ocorreu uma expansão de $28 \%$ no grupo de professores com nível superior completo que ministrava aulas no ensino fundamental. Sobre a qualificação e melhoria na formação do professor, o autor afirmou: 
1. O número de professores de ensino fundamental da rede pública cresceu acima daqueles pertencentes à rede privada a partir da implantação do FUNDEF: 9,7\% em 1998, 16\% em 1999 e 22\% em 2000. E o melhor desempenho foi obtido justamente nas regiões mais pobres (Nordeste e Norte, apresentando, respectivamente, crescimento de $47 \%$ e $31 \%$ acima da rede privada no ano 2000). Quando o corte da informação é feito pelo Índice de Condição de Vida, também fica claro que o melhor desempenho foi dos municípios mais pobres, com crescimento médio de $47 \%$ maior que o das escolas privadas no ano 2000.

2. O índice de número de anos de estudos dos professores da rede pública também cresceu mais rapidamente que os da rede privada, com um diferencial de 1,5\% em 1999 e de 2,5\% em 2000. Mais uma vez o melhor desempenho deu-se nas regiões e municípios mais carentes. Nas regiões Nordeste e Norte os índices para o ano 2000 foram, respectivamente, de $5 \%$ e $6 \%$ acima dos índices da rede privada. Nos municípios de baixo Índice de Condição de Vida o crescimento acima daquele apresentado pela rede privada foi de $5 \%$. (MENDES, 2004, p. 11)

No entanto, não se pode desconsiderar que a precarização, tanto da formação (ou mesmo a ausência de uma formação específica) quanto das condições de trabalho e materiais da maior parcela dos professores que atuavam no ensino fundamental, não constituía exceção, e sim regra.

Sampaio e Marin (2004) observaram que o processo de desqualificação e desvalorização do trabalho docente, aqui entendido como precarização, tem seus primórdios ainda na primeira metade do século XX e não se limita apenas à questão salarial ou às condições de trabalho. Conforme Oliveira (2004), as reformas dos anos 1990, tanto do Estado quanto educacionais, fomentaram o processo de desvalorização e desqualificação da atividade docente. Esse processo resultou na perda da autonomia, ou seja, da possibilidade de participar da elaboração e organização de seu trabalho.

Aliado a esse fator, situações como o aumento do número de professores com contrato temporário, a diminuição de salários, a inexistência de um piso salarial nacional, a perda de garantias trabalhistas resultantes da reforma do Estado, as perdas e/ou a não recomposição dos salários ampliaram a precarização do trabalho docente nos 1990. Nesse sentido, parcela considerável dos 15\% que o Fundef destinava à valorização do magistério foi utilizada na formação de professores em precárias condições para o exercício de sua atividade.

Davies (2001) constatou que no período 1998-2000 ocorreu uma mudança na nomenclatura dos itens que compunham a remuneração e/ou a extinção de gratificações, transformadas em salários. Quanto aos números 
relativos ao período entre janeiro de 1998 e junho de 2000 ," $39 \%$ das redes de ensino teriam concedido aumentos superiores a $70 \%, 29 \%$ das redes, entre $20 \%$ e $50 \%$, e o restante, ganhos de até $20 \%$ ", índices que, segundo o autor, poderiam ter sido obtidos não apenas com recursos do Fundef, mas também com aumentos na arrecadação estadual e municipal (DAVIES, 2001, p. 31).

Conforme Pinto (2002, p. 115), o Fundef,

em suma, foi uma resposta do Governo $\mathrm{FHC}$ ao não cumprido Acordo Nacional de Valorização do Magistério da Educação Básica. Só que, em lugar de um Piso Nacional de Salário de R\$300, em valores de julho de 1994, entra um provável Salário Médio de R\$300, em valores de dezembro de 1996. É escusado dizer que salário médio é completamente diferente de piso salarial.

Quanto à valorização do magistério, Verhine (2005, p. 19-20) pontua que

os dados indicam que, ao contrário do esperado, os salários (com valores corrigidos pelo IGP-DI) baixaram em muitos estados e municípios estudados. Houve, no entanto, algumas exceções, como, por exemplo, os sistemas estaduais de Paraíba (+70\%) e Maranhão (+130\%). Em muitas localidades pesquisadas, as limitações de aumento salarial foram atribuídas à necessidade de investir na habilitação de professores leigos. E, de fato, foram observados avanços em relação à qualificação geral do magistério, especialmente em zonas rurais, embora a presença de professores leigos ainda continue integrando o cenário educacional brasileiro. Outro dado de interesse é a descoberta de que, em vez de aumentar os salários, muitos municípios adotaram a prática do abono ou da distribuição do saldo dos $60 \%$, de uma só vez, a título de gratificação ("rateio"), o que pode ser entendido como uma estratégia para não comprometer as finanças do município, caso o FUNDEF não permaneça.

Sob o prisma da focalização no nível fundamental, dois aspectos são significativos para entender o que caracterizou o sentido de valorização do magistério no Fundef. Em primeiro lugar, o reconhecimento da existência de profissionais sem qualificação e, portanto, com poucas condições de executarem a política da eficiência gerencial. Em segundo lugar, o fato de que a remuneração, inferior ao mínimo necessário, além de competir para a ineficácia e ineficiência do modelo de gestão educacional pretendido, gerava uma sistemática oposição. Em última análise, embora reconhecendo as necessidades de valorização do magistério, as medidas tomadas privilegiavam o investimento a custo baixo.

No sentido de uma efetiva política de valorização do magistério, cabe destacar que Nóvoa (2007) identificou como elementos estruturais: o 
exercício de atividades em tempo integral, o estabelecimento de um suporte legal para o exercício da profissão, um conjunto de normas e valores e um corpo de conhecimentos e técnicas de instrumentação que identifiquem o profissional, a constituição de associações de classe e o controle de admissão dos membros pelos próprios pares. Entretanto, constatou-se, segundo pesquisa realizada por Almeida, Cunha e Araújo (2009, p. 9), o impacto da valorização do magistério em municípios do estado da Bahia, após o Fundef.

Precarização do exercício do magistério em decorrência do estabelecimento dos contratos temporários de prestação de serviços. Esses contratos são estabelecidos no prazo de duração do período letivo, ausentando os municípios das responsabilidades com o pagamento de férias, $13^{\circ}$ salário e outras gratificações atreladas à qualificação profissional. A base para o valor pago aos professores que são contratadas para lecionar em escolas públicas municipais, em geral, tem sido o salário mínimo. Esses contratos são cedidos por determinação do gestor municipal e, por vezes, são utilizados como forma de atendimento a acordos políticos. Desse modo, a qualificação desses profissionais não se constitui em requisito principal na seleção dos contratados. Além disso, os contratos temporários funcionam como instrumentos que dificultam a realização de concursos públicos para preenchimento de vagas para o quadro efetivo do município. Ainda assim, os sistemas municipais de ensino enfrentam problemas na realização de concursos, pois os gestores recorrem à questão da ausência de recursos financeiros como empecilho, além da responsabilização com relação aos limites de gastos com pagamento de pessoal a partir das determinações da Lei de Responsabilidade Fiscal.

Portanto, ressente-se ainda de uma política nacional de valorização do magistério, permanecendo a precarização da profissão e das condições de trabalho, bem como uma cartorialização no momento do contrato ou demissão dos profissionais. Assim, é possível constatar a utilização do Fundef em consonância com a supressão de algumas das conquistas, mas envoltas em um arsenal propagandístico que amortecia a supressão de direitos e exaltava as reformas neoliberais. Observa-se que se prometia uma ampliação dos salários, mas parcela considerável do magistério teve suprimidas gratificações que resultavam em uma ampliação dos vencimentos. A formação continuada foi realizada, em muitos casos, a distância, ou com a aquisição de programas de instituições privadas, pagas com verbas públicas. A formação foi realizada em períodos de férias ou recesso dos professores. 
A VALORIZAÇÃO DOS PROFISSIONAIS DA EDUCAÇÃO NO FUNDEB: O “AVANÇO POSSIVEL"

A vitória de Luís Inácio Lula da Silva nas eleições presidenciais de 2002 foi entendida por diversos setores da sociedade brasileira como uma real possibilidade de organização de um fundo constitucional que, de forma efetiva e definido como política de Estado, atendesse às necessidades da educação básica. A experiência histórica acumulada, a participação dos setores organizados da sociedade, os estudos, as pesquisas e a perspectiva de mudanças na organização política do Brasil com as eleições de 2002 sinalizavam para as possibilidades de construção de um novo modelo ou de um aperfeiçoamento do modelo existente de financiamento que de fato contemplasse toda a educação básica e contribuísse para a efetivação de uma educação de qualidade social.

Entretanto, o processo histórico que caracterizou a passagem do Fundef ao Fundeb evidencia a manutenção de limitações que caracterizaram o primeiro. Todavia, deve-se observar, no tocante à concepção política, a superação da focalização em uma etapa, com a ampliação para todas as etapas da educação básica; a possibilidade de maior participação da sociedade nos CACS, entre outros. Em 19 de dezembro de 2006, foi aprovada a EC no 53/2006, que em 20 de junho de 2007 foi regulamentada pela Lei $n^{\circ}$ 11.494 e pelo Decreto $n^{\circ} 6.253 / 2007$. Em relação ao papel do Executivo na construção do Fundeb, permanecia o antagonismo entre o discurso e a prática e, ao mesmo tempo, uma hesitação entre a ruptura com a política focalizada ou o "avanço possível".

Em 20 de dezembro de 2006, o Governo Federal edita a EC n ${ }^{\circ} 53$, que deu nova redação aos arts. 70, 23, 30, 206, 208, 211 e 212 da Constituição Federal e ao art. 60 do Ato das Disposições Constitucionais Transitórias: destacou a inclusão da educação infantil e das creches; propôs um piso salarial nacional aos profissionais da educação pública e a complementação da União, seguindo critérios de progressividade até 2010, percentuais anuais de participação dos impostos estaduais e municipais até constituírem o total de 20\% (BRASIL, 2003). Em 28 de dezembro de 2006, editou-se a MP n 339, que regulamentava o artigo 60 das Disposições Constitucionais Transitórias, criando o Fundeb, regulamentado pela Lei ${ }^{\circ} 11.494$, de 20 de junho de 2007, estabelecendo sua vigência até dezembro de 2020 (BRASIL, 2007).

Conforme a visão institucional, o Fundef promoveu um impulso na universalização do ensino fundamental. Contudo, não foi capaz de suprir a "ausência de uma política que concorra para a indistinta universalização 
do atendimento, sustentada por mecanismos que assegurem melhoria qualitativa do ensino oferecido, com valorização dos profissionais da educação" (FERNANDES, 2006a, p. 146). Ao Fundeb, caberia esse papel de preenchimento dessa lacuna (LIMA; DIDONET, 2006). Além disso, o Fundo manteria a divisão de responsabilidades com relação ao que está instituído na Constituição de 1998, mas sugerindo uma maior participação do governo federal. Propunha

uma ampla redistribuição dos recursos financeiros vinculados à educação básica, adotando como critério o número de alunos matriculados por nível de ensino no âmbito de cada rede (estadual ou municipal) e a garantia de um investimento mínimo por aluno/ ano, a ser fixado anualmente, que assegure efetivas condições de se alcançar um adequado padrão de qualidade do ensino. (FERNANDES, 2006b, p. 148)

Com relação à valorização do magistério, cabe destacar que, com a participação de sindicatos, associações de professores, incluindo a CNTE, elaborou-se uma proposta de ampliação para $80 \%$ do percentual do Fundeb, voltado para os gastos com salários dos profissionais da educação. A EC nº $53 / 2006$ destinava $60 \%$ dos recursos para os salários dos profissionais da educação, englobando os profissionais da educação escolar pública e os profissionais do magistério público da educação básica. No entanto, a Lei $\mathrm{n}^{\circ}$ 11.494/2007 definiu:

Art. 22. Pelo menos $60 \%$ (sessenta por cento) dos recursos anuais totais dos Fundos serão destinados ao pagamento da remuneração dos profissionais do magistério da educação básica em efetivo exercício na rede pública.

Parágrafo único. Para os fins do disposto no caput deste artigo, considera-se: I - remuneração: o total de pagamentos devidos aos profissionais do magistério da educação, em decorrência do efetivo exercício em cargo, emprego ou função, integrantes da estrutura, quadro ou tabela de servidores do Estado, Distrito Federal ou Município, conforme o caso, inclusive os encargos sociais incidentes;

II - profissionais do magistério da educação: docentes, profissionais que oferecem suporte pedagógico direto ao exercício da docência: direção ou administração escolar, planejamento, inspeção, supervisão, orientação educacional e coordenação pedagógica;

III - efetivo exercício: atuação efetiva no desempenho das atividades de magistério previstas no inciso II deste parágrafo associada à sua regular vinculação contratual, temporária ou estatutária, com o ente governamental que o remunera, não sendo descaracterizado por eventuais afastamentos 
temporários previstos em lei, com ônus para o empregador, que não impliquem rompimento da relação jurídica existente. (BRASIL, 2007)

Ficou estabelecido, pela Lei $n^{\circ} 11.494 / 2007$, o percentual de "pelo menos" $60 \%$ a ser aplicado aos salários dos "profissionais do magistério", definindo, legalmente, quem se enquadrava nessa categoria e excluindo os demais profissionais da educação pública.

É preciso considerar que o piso salarial nacional, como garantia de valorização do magistério, não deveria ter como referência os atuais salários, e sim construir um novo patamar, em especial, caso sejam consideradas as disparidades regionais e intrarregionais do país. Como a possibilidade de evolução das receitas de muitos municípios e de alguns estados é muita pequena e a complementação da União aos recursos do Fundeb permanece em percentuais discutíveis, as possibilidades de melhoria salarial são pouco prováveis. Assim como no Fundef, muitos governos provavelmente continuarão limitando-se ao percentual de $60 \%$ com o pagamento dos salários do magistério, excluindo os demais recursos vinculados à MDE. Também cabe observar que os governos podem, com a conivência dos Tribunais de Contas, "incluir os aposentados da educação nos 60\%, como fez impunemente o governo estadual de São Paulo em 2001 (e talvez em outros anos também) que destinou ilegalmente cerca de $\mathrm{R} \$ 1,26$ bilhão do Fundef para pagar os inativos" (DAVIES, 2008, p. 53-54).

Outra contradição apontada para valorizar o magistério é que os $60 \%$, por se tratar de percentual bruto, abrangem as contribuições previdenciárias e outras, e resultam numa redução de até $10 \%$ do valor destinado ao magistério. ${ }^{1}$

Mesmo considerando o Fundeb como um fenômeno recente, em termos de organização do financiamento da educação básica no Brasil, é necessário avaliar, entre outros aspectos, que, embora a lei esteja sendo cumprida e

sua concepção equalizadora seja mais tímida que a do Fundef, na prática, tem representado maior aporte de recursos por parte da União ao ensino básico. $\mathrm{O}$ impacto das políticas de fundos é conhecido. Ampliaram o atendimento das redes municipais, inclusive no Nordeste, reduziram a desigualdade de recursos disponíveis entre diferentes redes no interior de cada estado, aumentaram os salários aviltantes existentes anteriormente à sua implantação (salários inferiores a um salário mínimo), impulsionaram o processo de universalização do ensino fundamental. No entanto, a limitação dos montantes utilizados pela complementação da União, no caso do Fundef por não cumprimento da legislação, e no caso do Fundeb, por limitação do 
montante na lei, reduziu o impacto equalizador que as propostas poderiam ter. (OLIVEIRA; SOUZA, 2010, p. 28)

A consolidação de um mecanismo de financiamento da educação básica não se dissocia de uma dimensão politico-econômica e de ações concretas por parte do governo federal. Dessa forma, uma política econômica conservadora, a manutenção de ajustes fiscais e um direcionamento para a manutenção do superávit primário e a ausência de um federalismo fiscal e de um regime de colaboração entre os entes federativos limitam o desenvolvimento das políticas de financiamento educacional, mantendo o caráter de continuidade e uma política do "avanço possível".

\section{CONSIDERAÇÕES FINAIS}

Consideramos que a compreensão do processo histórico de valorização e precarização dos trabalhadores da educação constitui elemento central no contexto do financiamento da educação no Brasil. Desta forma, observamos que é significativo o entendimento de que o financiamento da educação é, como política pública, expressão de uma concepção de Estado, aqui entendido em uma acepção ampla, envolvendo sociedade civil e sociedade política, bem como o contexto, os embates, os desenvolvimentos e as contradições históricas em que estas se constituem (GRAMSCI, 2007) e as condições objetivas em que se efetivam a relação entre educação e sociedade (DOURADO, 2010).

Neste sentido, consideramos significativo refletir sobre as contradições históricas que se desenvolveram no Brasil ao longo de séculos, funcionando como elementos que restringiram a universalização e a efetivação de um projeto educacional que garanta o acesso e a permanência, resultados satisfatórios para os alunos e a sociedade, bem como a constituição de uma política de Estado para a educação. Em particular, se refletirmos sobre a educação pública, considerando em especial a educação básica, observaremos que ela tende a refletir as disparidades de um país de dimensões e desigualdades continentais.

A reflexão sobre esses fundos constitucionais ou subvinculações também tem o mérito de fazer emergir, e ao mesmo tempo publicizar, os debates sobre temas como: qualidade na educação; redistribuição de recursos públicos; regime de colaboração; valorização dos profissionais da educação; papel da União na educação; acompanhamento e controle social dos recursos e, especialmente, educação como direito. 
No contexto das políticas de financiamento da educação e, em particular, do Fundef e do Fundeb, ganha relevância a problemática da valorização dos profissionais da educação, considerados como protagonistas para a consolidação de uma educação de qualidade social. Neste sentido, observamos, em primeiro lugar, que o entendimento sobre "profissionais da educação" manteve a dimensão restrita à carreira do magistério, excetuando, ao contrário do entendimento das entidades ligadas aos trabalhadores da educação, os demais profissionais que se situam no âmbito da escola. Ficou estabelecido pela Lei $n^{\circ} 11.494 / 2007$ o percentual de "pelo menos" $60 \%$ a ser aplicado aos salários dos "profissionais do magistério", definindo, legalmente, quem se enquadrava nessa categoria e excluindo os demais profissionais da educação pública. Em segundo lugar, outra contradição apontada quanto à valorização do magistério residiu no fato de os $60 \%$, por se tratar de percentual bruto, abrangerem as contribuições previdenciárias e outras, o que significa uma redução de até $10 \%$ do valor destinado ao magistério.

Considera-se, portanto, que, em que pese os avanços de ampliação a toda educação básica e uma maior definição da participação e controle social nos CACS, entre outros aspectos, o que se estabeleceu da parte do governo foi o discurso do "avanço possível" e a política de concessões numa dimensão restrita. Em outras, palavras, sem o estabelecimento de uma política de Estado para a educação e com a continuidade de uma política de ações emergenciais para demandas instantâneas.

Resulta refletir que a participação e o controle social dos recursos e das políticas públicas de financiamento da educação, particularmente no nível básico, constitui um dos mecanismos fundamentais para a superação das desigualdades históricas no campo da educação brasileira. No entanto, resta muito a realizar. Observe-se que a meta 17 do Projeto de Lei (PL) n8.035/2010, que estabelece o Plano Nacional de Educação, propõe a valorização dos profissionais do magistério e não diz nada sobre os profissionais da carreira de assistência à educação. A meta 20 do referido PL dispõe sobre o percentual do Produto Interno Bruto (PIB), a ser aplicado na educação brasileira, a partir de 2020, no limite de 7\%. É preciso considerar que em 2010 seriam necessários 7\% do PIB apenas para elevar o Piso Nacional Salarial dos Professores da Educação Básica Brasileira (AMARAL, 2011), previsto na EC n 59/2009 a todos os profissionais que atuam nesse nível. Desta forma, mantido o contexto atual, permanecerá o abismo entre proposta e ação no campo das políticas públicas de valorização dos profissionais da Educação Básica no Brasil. 
FROM THE DISCOURSE OF VALORIZATION TO THE REALITY OF PRECARIOUSNESS: EDUCATION PROFESSIONALS IN THE CONTEXT OF FUNDEF AND FUNDEB

ABSTRACT: This paper, in the form of an exploratory study, based on research into the historical origins and perspectives of policies for constitutional funding for Basic Education in Brazil, discusses the policy of valorizing teaching according to the constitutional funding referred to, notably the Fund for the Enhancement of Fundamental Education and Valorization of Teaching (Fundef) and the Fund for the Promotion of Basic Education and Valorization of Education Professionals (Fundeb). A survey was conducted of all the legislation pertinent to educational funding, in particular, that of Brazilian basic education, the 1988 Constitution, the LDB 9394/1996, constitutional amendments, resolutions and position papers of the National Council for Education, the Ministry of Education and relevant literature. Having done so, it can be stressed that it is possible to consider that, historically, the problem involving the valorization of teaching is one of the questions which, as part of educational policies and funding, is a key issue in discourse, although in general practice, it remains relegated to the background or is neglected by the government.

KeYwORDs: Financing basic education. Precariousness. Valorization of education professionals. Fundef. Fundeb.

DEL DISCURSO DE LA VALORIZACIÓN A LA REALIDAD DE LA PRECARIZACIÓN: LOS PROFESIONALES DE LA EDUCACIÓN EN EL CONTEXTO DEL FUNDEFY DEL FUNDEB

RESUMEN: El presente trabajo, construido como estudio exploratorio a partir de una investigación sobre los orígenes históricos y las perspectivas de la política de los fondos constitucionales en el contexto del financiamiento de la Educación Básica en Brasil, discute la política de valorización del magisterio de acuerdo con los mencionados fondos constitucionales, destacándose el Fondo de Valorización de la Enseñanza Fundamental y de Valorización del Magisterio (Fundef) y el Fondo de Desarrollo de la Educación Básica y de Valorización de los Profesionales de la Educación (Fundeb). Se realizó un levantamiento en el conjunto de la legislación pertinente al financiamiento de la educación, en particular, de la educación básica brasileña, la Constitución Federal de 1988, la Ley de Directrices y Bases (LDB) 9394/1996, las Enmiendas Constitucionales, las resoluciones y pareceres del Consejo Nacional de Educación, del Ministerio de Educación y Cultura (MEC) y la literatura pertinente. Al final, se destaca que, es posible considerar que, históricamente, la problemática que envuelve la valorización del magisterio se presenta como uno de los asuntos que, como integrante de las políticas educacionales y de financiamiento, asume centralidad en el discurso, aunque, en general, en la práctica, permanezca relegado a un segundo plano o negligenciado por el poder público.

PalABRAS-Claves: Financiamiento de la educación básica. Precarización. Valorización de los profesionales de la educación. Fundef. Fundeb. 


\section{NOTA}

1. Em 16 de julho de 2008 foi sancionada pelo Presidente da República a Lei nº $11.738 / 2008$ (BRASIL, 2008), que regulamentou o piso salarial profissional nacional para os profissionais do magistério público da educação básica a que se refere o artigo 60 das Disposições Constitucionais Transitórias. O piso inicialmente regulamentado era de $\mathrm{R} \$ 950,00$ (novecentos e cinquenta reais) para uma jornada de 40 horas semanais (art. $2^{\circ}$ ). Além do valor do piso, a lei dispõe, no parágrafo segundo, que por "profissionais do magistério público da educação básica entendem-se aqueles que desempenham as atividades de docência ou as de suporte pedagógico à docência, isto é, direção ou administração, planejamento, inspeção, supervisão, orientação e coordenação educacionais, exercidas no âmbito das unidades escolares de educação básica, em suas diversas etapas e modalidades, com a formação mínima determinada pela legislação federal de diretrizes e bases da educação nacional" (BRASIL, 2008). Possibilita ainda que $1 / 3$ da jornada de trabalho seja para o desenvolvimento de atividades de coordenação e, no art. 5, estabelece o reajuste anual, tendo por referência, conforme o"parágrafo único do referido artigo", "o mesmo percentual de crescimento do valor anual mínimo por aluno referente aos anos iniciais do ensino fundamental urbano, definido nacionalmente, nos termos da Lei no 11.494, de 20 de junho de 2007" (BRASIL, 2008), entre outros aspectos. A aprovação da Lei no 11.738/2008 suscitou questionamentos de governadores, que entraram com uma Ação de Inconstitucionalidade no Supremo Tribunal Federal. Os governadoress dos estados do Rio Grande do Sul, Santa Catarina, Paraná, Mato Grosso do Sul e Ceará argumentavam que os custos com a folha de pagamento poderiam ultrapassar o que é estabelecido pela Lei de Responsabilidade Fiscal, bem como a referida lei poderia representar o fim da autonomia dos estados e municípios. No entanto, em 6 de abril de 2011, o Plenário do Supremo Tribunal Federal aprovou por oito votos contra um o Piso Nacional Salarial dos Professores da Educação Básica.

\section{REFERÊNCIAS}

ALMEIDA, C. da C. G. de; CUNHA, M. C.; ARAÚJO, R. B. M. de. Para além da formação: as políticas de valorização do magistério público municipal na Bahia. REUNIÃO ANUAL DA ANPED, 32, 2008 Caxambu. MG. Anais... Caxambu, MG: ANPED, 2008, p. 1-15. Disponível em: <http://www.anped.org.br/reunioes/32ra/arquivos/trabalhos/GT08-5666--Int. pdf $>$. Acesso em: 20 nov. 2009.

AMARAL, N. C. Um novo Fundef? As ideias de Anísio Teixeira. Educação \& Sociedade, Campinas, SP, v. 12, n. 75, p. 22-290, ago. 2001.

. O novo PNE e os recursos para o financiamento da educação no Brasil: os recursos como um percentual do PIB. Cadernos CEDES. III Seminário de Educação Brasileira, Campinas, SP, 28 de fevereiro a 03 de março de 2011, p. 1-14. Disponível em: <http:// www.cedes.unicamp.br/seminario3/nelson_amaral.pdf >. Acesso em: 12 abr. 2011. 
ARELARO, L. R. G. FUNDEF: uma avaliação preliminar dos dez anos de sua implantação. 30a REUNIÃO DA ANPED, Caxambu, MG. Anais... Ribeirão Preto: ANPED, 2008, p. 1-15. Disponível em:< http://www.anped.org.br/reunioes/30ra/trabalhos/GT05-3866--Int. pdf > . Acesso em: 10 mar. 2009.

BRASIL. Lei n 9.394, de 20 de dezembro de 1996. Estabelece as diretrizes e bases da educação nacional. Brasília: Presidência da República, Casa Civil, Subchefia para Assuntos Jurídicos. Disponível em: <http://www.planalto.gov.br/ccivil_03/Constituicao/ Emendas/Emc/emc59.htm>. Acesso em: 10 nov. 2009.

. Emenda Constitucional n53/2006. Dá nova redação aos arts. 70, 23, 30, 206, 208, 211 e 212 da Constituição Federal e ao art. 60 do Ato das Disposições Constitucionais Transitórias. Diário Oficial da União. Brasília: Imprensa Nacional, edição 243, 20 de dezembro de 2006, Sessão 1, p. 1-4.

. Lei $n^{\circ} 11.494$, de 20 de junho de 2007. Regulamenta o Fundo de Manutenção e Desenvolvimento da Educação Básica e de Valorização dos Profissionais da Educação - Fundeb, de que trata o art. 60 do Ato das Disposições Constitucionais Transitórias; altera a Lei no 10.195, de 14 de fevereiro de 2001; revoga dispositivos das Leis nºs 9.424, de 24 de dezembro de 1996, 10.880, de 9 de junho de 2004, e 10.845, de 5 de março de 2004; e dá outras providências. Brasília: Presidência da República, Casa Civil, Subchefia para Assuntos Jurídicos. Disponível em: <http://www.planalto.gov.br/ ccivil/_Ato2007-2010/2007/Lei/L11494.htm>. Acesso em: 10 ag. 2007.

. Lei no. 11.738, de 16 de julho de 2008. Regulamenta a alínea "e" do inciso III do caput do art. 60 do Ato das Disposições Constitucionais Transitórias, para instituir o piso salarial profissional nacional para os profissionais do magistério público da educação básica. Brasília, Presidência da República, Casa Civil, Subchefia para Assuntos Jurídicos.Disponível em:<http://planalto.gov.br/ccivil_03/_Ato2007-2010/2008/Lei/ L11738.htm>. Acesso em: 12 abr. 2011.

COSTA, B. L. D.; DUARTE, V. C. O Fundef e a valorização do magistério em Minas Gerais: alcances e limites de um mecanismo institucional de indução. Texto para Discussão $n^{\circ}$. 07, Escola de Governo da Fundação João Pinheiro, Belo Horizonte, maio 2004.

DAVIES, N. O FUNDEF e as verbas da educação. São Paulo: Xamã, 2001.

FUNDEB: a redenção da educação básica? Campinas, SP: Autores Associados, 2008.

DOURADO, L. F. Avaliação do Plano Nacional de Educação 2001-2009: questões estruturais e conjunturais de uma política. Educação \& Sociedade, Campinas, SP, v. 31, n. 112, p. 677-705, jul./set. 2010. Disponível em: <http://www.cedes.unicamp.br>. Acesso em: 7 dez. 2010.

FERNANDES, F das C. Do FUNDEF ao Fundeb: mudanças e avanços. In: LIMA, M. J. R.; DIDONET, V. FUNDEB: avanços na universalização da educação básica. Brasília: MEC-INEP, 2006a. p.117-144. 
FERNANDES, A. S. Políticas Públicas: Definição, Evolução e o Caso Brasileiro. São Paulo: ANDI, 2006b. p. 1-19. Disponível em: <http://serv01.informacao.andi.org.br/ b6d71ce_114f59a64cd_-7fcc.pdf >. Acesso em: 19 mar. 2010.

GRAMSCI, A. Cadernos do cárcere - Maquiavel, Notas sobre o Estado e a política. Rio de Janeiro: Civilização Brasileira, v. 3, 2007.

LIMA, M. J. R.; DIDONET, V. FUNDEB: avanços na universalização da educação básica. Brasília: MEC-INEP, 2006.

MENDES, M. J. Análise das irregularidades na administração municipal do FUNDEF: constatações do programa de fiscalização a partir de sorteios públicos da Controladoria-Geral da União. São Paulo: Transparência Brasil, dez. 2004. p. 1-17.

NÓVOA, A. Desafios do trabalho do professor. São Paulo: Sindicato dos Professores do Estado de São Paulo, 2007.

OLIVEIRA, D. A. de. A reestruturação do trabalho docente: precarização e flexibilização. Educação \& Sociedade, Campinas, SP, v. 25, n. 89, p. 1127-1144, set./dez. 2004. Disponível em: <http://www.cedes.unicamp.br> . Acesso em: 10 maio 2011.

OLIVEIRA, R. P. de; SOUZA, S. Z. Introdução. In: OLIVEIRA, R. P. de (Org.). Educação e federalismo no Brasil: combater as desigualdades, garantir a diversidade. Brasília: Unesco, 2010. p. 13-38.

PINTO, J. M. R. Financiamento da educação no Brasil: um balanço do governo FHC (1995-2002). Educação \& Sociedade, Campinas, SP, v. 23, n. 80, p. 108-135, set. 2002.

SAMPAIO, M. das M. F.; MARIN, A. J. Precarização do trabalho docente e seus efeitos sobre as práticas curriculares. Educação \& Sociedade, Campinas, SP, v. 25, n. 89, p. 1203-1225, set./dez. 2004. Disponível em: < http://www.cedes.unicamp.br> . Acesso: 9 maio 2011.

SEMEGHINI, U. C. (2001a). FUNDEF: uma revolução silenciosa. Brasília: MEC, 2001. Disponível em: <http://www3.sef.sc.gov.br/publicacoes/revolucao_FUNDEF.pdf> . Acesso em: 3 maio 2007.

. (2001b). FUNDEF: corrigindo distorções históricas. Em Aberto, Brasília, INEP/ MEC, v. 18, n. 74, p. 43-57, dez. 2001.

VERHINE, R. E. Levantamento do custo-aluno-ano em escolas de Educação Básica que oferecem condições de oferta para um ensino de qualidade $-2^{\text {a }}$ Etapa. Salvador: MEC-INEP, 2005.

WeLLINGTON fERREIRA DE JESUS: Doutor em Educação pela Universidade Federal de Goiás. Professor do Programa de Pós-Graduação em Educação da Universidade Católica de Brasília.

E-mail:wellingtonfj@smail.com 